\title{
Medicina do Trabalho: subciência ou subserviência? Uma abordagem epistemológica
}

\author{
Labor M edicine: sub-science or subserviency? \\ An epistemological approach
}

Luiz Carlos Fadel de Vasconcellos ${ }^{1}$

Wanderlei Antonio Pignati ${ }^{2}$

${ }^{1}$ Escola Nacional de Saúde

Pública, Fiocruz. Rua

Leopoldo Bulhões 1480,

Manguinhos. 21041-210

Rio deJaneiro RJ.

elfadel@globo.com

2 Universidade Federal do

$M$ ato Grosso.

\begin{abstract}
This article discusses a disquieting issue in the field of workers' health, the mission of the labor physician in the context of a change in the model of public politics with regard to the relation health and work that began with theestablishment of the new Unified Health System in Brazil. The paper focuses on epistemological questions like M edicine being or not a science and analyzes the mission of Labor M edicine on the basis of a short historical analysis of its development and its appropriation by the production systems and institutional trajectory since the appearance of the first factory physician. The study comes to the conclusion that Labor M edicine is not on a level with the ethical and scientific principlestraditionally expected from $M$ edicine and its special fields, understanding this branch of medicineasa practice subordinated to other hegemonic and not scientific variables. Finally, this article remits to the debate about the contradictions involving the construction of the field of workers' health in Brazil.
\end{abstract}

Key words Labor M edicine, Workers' health, M edical science
Resumo 0 artigo traz ao debate um tema inquietantena área de saúde do trabal hador, qual seja, o papel do médico do trabal ho, no contexto deuma mudança de paradigma das políticas dirigidas às relações saúde trabalho, a partir do advento do Sistema Ú nico de Saúde. Buscando ater-seàs questões epistemológicas deser ou não a medicina uma ciência, analisa-seo papel da M edicina do TrabaIho neste contexto, dentro de uma breve análise histórica de seu desenvolvimento, sua apropriação pela lógica dos sistemas produtivos e sua trajetória institucional, desde o surgimento do primeiro médico de fábrica. Conclui-se pela interpretação de quea M edicina do Trabal ho não atende aos postulados éticos e científicos que se requer historicamente da medicina edesuas especialidades médicas, entendendo aquela como prática subserviente a outras variáveis, hegemônicas e não científicas. Além disto, remete o debate às contradições conceituais que envolvem a construção da área de saúde do trabalhador no Brasil.

Palavras-chave M edicina do Trabalho, Saúde do trabalhador, Ciência médica 


\section{Medicina: ciência?}

Sedefinir ciênciaéum desafio hermenêutico quase insondável, situar a medicina como ciência pode ser uma temeridade epistemológica. Impregnada de avaliações subjetivas das humanidades, a medicina é instigante neste dilema de ser ou não ciência.

A ciência, mesmo, ser ou não ser, permanentemente revisitada em seus pilares dogmáticos que Ihe sustentam conceitualmente - as suas capacidades de previsibilidade, exatidão, comprovação, reprodutibilidade, refutabilidade, como assinalaria Popper ${ }^{1}$, e instabilidade paradigmática, como acrescentaria Kuhn², entre tantas variáveis de categorização - instiga o debate sobrea medicina: ciência ou não. Todavia, independentemente do desfecho deste debate, a possibilidade de se estabelecer critérios científicos de análise às práticas e metodologias arroladas no campo do conhecimento médico supõe uma necessária demarcação epistêmica de seus objetos de alcance. Parece que é desta forma que a filosofia da ciência tem se comportado, ao se referir ao campo da saúde e às disciplinas que lhe conformam, com destaque para a medicina, ao buscar balizamentos críticos de suas práticas.

Por certo, a medicina, ou ciência médica, como é expressivamente, etalvez descuidadamente, rotulada, comporta um sem-número de disciplinas do conhecimento científico, para alcançar seu(s) objetivo(s). Certo, também, quesefunda em conhecimentos alicerçados em subjetividades movediças, incapazes de resistir ao crivo epistemológico. Doislados de uma moeda em que se pode questionar o seu valor de face, mas será moeda em última instância.

A medicina poderá ser encarada tão somente como uma técnica, conjunto de habilidades artificiais disponibilizadas para o desígnio do processo teleológico da vida, dada nesta a sua falibilidade e ineficácia para se perpetuar ${ }^{3}$.

$E$, como técnica ou conjunto harmonizado de técnicas, a medicina, sistematizada no seu ato concreto de devir - 0 ato médico - estaria mais suscetível ao crivo deontológico, por conta desua aplicação e dos resultados dela decorrentes, do que ao crivo epistêmico propriamente dito.

Defendendo a idéia de que a medicina não se trata de ciência, a despeito de sua emergência como tal na contemporaneidade "tecnologizada" do ato médico, bem se delimita o quanto à medicina se retira o caráter estritamente científico, ao lidar ela com a manutenção da vida da espécie humana: La vida no puede esperar a que las cien- cias expliquen científicamenteel U niverso... El atributo más esencial de la existencia es su perentoriedad: la vida es siempre urgente ${ }^{4}$.

O corre que a fronteira entre o comportamento do "fazer médico" e o conteúdo dos postulados "científicos" e não científicos que lhe subsidiam carece de limites precisos em que se possa assegurar onde começam e terminam: a ética do ato médico, a relevância política de sua aplicação e a certificação da indenidade científica que Ihe embasa. Eis o desafio maior desse debate.

Se nos pusermos em acordo de que, em última análise, cada ato médico, de per si, traduz uma trajetória cumulativa de conhecimentos científicos recheados de observações empíricas e singularizados, estaremos diante do dilema: não será cada ato médico - expressão emblemática da práxis da medicina - uma invenção não patenteável ou ainda não patenteada? Por outro lado, o mesmo recheio do pragmatismo individualizado em cada ato médico possui fortes temperos culturais, míticos, místicos e al eatoriamente determinados pela (in)consciência de cada criador e/ou executor do ato em si. Nesse caso, o fazer médico não será a expressão pura e simples do que mile narmente se rotulou de ars curandi? - uma pequena e singela obra de arte, ou a sua negação (?), no caso de a obra ser concluída, mas não conseguir atingir a finalidade "estética" da cura.

Não é o propósito desta discussão visualizar 0 ato médico como prática profissional corporativa de uma das inúmeras corporações nele implicadas - no caso da nossa discussão, o da corporação dos médicos propriamente ditos, foco, inclusive, de um intenso debate legal contemporâneo, no qual, sem maiores aprofundamentos, posicionamo-nos diante do ato médico de forma ecumênica e complacente dentro dos parâmetros cultural e socialmente estabelecidos, ao longo da sua trajetória histórica, qual seja, como prática interdisciplinarmente constituída egenerosamente receptiva a novas práticas.

Apenas, apoiados na sua emblematização, intentamos delimitar o objeto da abordagem epistemológica, a de que a medicina estaria ou não sujeita no laboratório reflexivo da validação dita científica. E, nesse caso, consideraremos o ato médico em si mesmo: a prática mais singularizada e atomizada desfechada pelo médico, como elemento simbólico representativo da medicina.

Podemos fazer incursões em qualquer uma das várias vias na encruzilhada deste tema, certos de que todas levarão ao mesmo ponto dechegada. Uma delas é a inexistência de uma ciência 
médica, mas somente o embasamento de seu ato pragmático final (o ato médico) num discurso em tudo científico. Calcada no discurso baseado em ciências puras, tais como a biologia, a fisiologia, a química e a física, entre outras, a medicina acaba por invocar a ciência como meio de validação da verdade de seu pragmatismo tecnicista, na medida em que ciência é sinônimo de verda$\mathrm{de}^{5}$.

Talvez, o que mais distancie a medicina e o conjunto de práticas que Ihe dão corpo da ciência seja o seu conteúdo teleológico, centrado na ética do comportamento finalístico, cuja essência é o valor intrínseco de fazer o bem, em princípio a qual quer custo, na direção da cura. Contudo, se na busca desse objetivo-mor (fazer o bem), a medicina vai beber na fonte das ciências quelhedão suportee consistência, equanto mais próxima do fundamento científico mais a medicina cure, ou seja, mais atinja seu desígnio essencial, mais ela se torna científica. Aproximações que nos fazem preservar a ideologia de medicina como ciência, ainda que ressalvadas suas tantas variáveis não científicas. Fato que coloca, de forma mais incisiva, a ciência médica e 0 ato médico na rota do ol har epistemológico sobre si. Não fora desse modo, 0 ato médico seria tão somente um ato de benemerência social, um ato político, um ato de curandeirismo, um ato de solidariedade humana, embora não deixe de ser uma amálgama de todos eles, mas sempre revestido de um caráter "científico", como assinalava Galeno (129-200) ainda no alvorecer da medicina como ciência: "Curto e hábil é o caminho da especulação, mas não conduz a nenhuma parte; longo e penoso éo caminho da experiência, mas nos leva a conhecer a verdade" ${ }^{\prime \prime}$.

\section{Medicina-ciência}

É nesse contexto, digamos galênico, que colocamos a medicina como ciêncial lato sensu. Seja para que desta premissa se reti rem os postulados que regem a validação de suas incursões, sob o prisma da crítica científica, seja para que nos disciplinemos na delimitação de conceitos, mesmo sabendo-os insuficientes para dar conta da complexidade arrolada no objeto conceituado.

Assim, a medicina-ciência se comporta como um grande afluente de ciências subjacentes e um escoadouro de subciências: suas ramificações as especialidades médicas. Sem o caráter de valoração qualitativa, e muito mais na linha de subordinação hierárquica, consideraremos nesta discussão as especialidades da medicina como subciências médicas. Evidentemente, que por se tratarem de derivações da ciência-mor que Ihes rege, as especialidades médicas seguem, em qualquer situação normativa, deôntica ou técnica, a "doutrina" da medicina-ciência: subciências, pois bem.

Hipócrates (460-377 a.C.), em sua sentença fundadora da medicina - o juramento - coloca o ente teleológico essencial da matéria: Eu juro, por Apolo, médico, por Esculápio, Higeia e Panacea, e tomo por testemunhas todos os deuses e todas as deusas, cumprir, segundo meu poder e minha razão, a promessa quese segue: [...] A plicarei os regimes para o bem do doente segundo o meu poder $e$ entendimento, nunca para causar dano ou mal a alguém. A ninguém darei por comprazer, nem re médio mortal nem um consel ho que induza a perda [...] Conservarei imaculada minha vida e minha arte [...] Em toda a casa, aí entrarei para 0 bem dos doentes... Se eu cumprir este juramento com fidelidade, que me seja dado gozar felizmente da vida e da minha profissão, honrado para sempre entre os homens; se eu dele me afastar ou infringir, o contrário aconteça"7.

Juramento este que se mantém como emblema do significado da arte médica ou da medicina-ciência, em nenhuma hipótese contestado ou repudiado ao longo desses 23 séculos, porquanto negá-lo seria negar a essência da matéria médica e sua finalidade.

Nesse contexto, a medicina e 0 ato médico que a corporifica têm, em última análise, o seu objeto de real ização concreta como ciência o bem do doente, o bem do paciente, o bem do ser humano sob o cuidado médico, enfim, o bem ou princípio da beneficência. $N$ ão há ressalvas. 0 princípio da beneficência tem como regra norteadora da prática médica, odontológica, psicológica e da enfermagem, entre outras, o bem do paciente, o seu bem-estar e os seus interesses, de acordo com oscritérios do bem fornecidos pela medicina, odontologia, psicologia e enfermagem. Fundamenta-se nesse princípio a imagem que perdurou do médico ao longo da história, e que está fundada na tradição hipocrática ${ }^{8}$.

Parece factível, portanto, que a mirada filosófica da ciência sobre a medicina considere que, a despeito deum desprovimento ideológico apriorístico da ciência em geral - uma "neutralidade" científica no seu objeto teleológico, que, a rigor, sabemos ser também questionável -, o obje to finalístico da medicina calcado numa ideologia e numa ética do "bem" não borra a silhueta científica da medicina. 
A idéia concreta de "bem", contudo, é vaga, em decorrência de valores principalmente culturais e místico-religiosos para defini-la e, por isso, extremamente variável em função do contexto histórico de cada sociedade em particular. M ais uma vez, a medicina, incorporando certa "trans-historicidade" em sua finalidade, vai se fundar na idéia de "bem" como cura ou, na sua impossibilidade, mitigação da dor edo sofrimento, a partir da utilização de seu aparato técnico e tecnológico.

Para a medicina, o "bem" finalístico a que se propõe alcançar é devolver ao ser humano sob o cuidado médico a forma mais condizente possível com o "andar natural das coisas da vida", em seu ambiente cultural e social, ainda que, como ensinava Galeno, vix medicatrix naturae, a força curativa da natureza muitas vezes prescinda da medicina e do médico - la idea de plantear la medicina como una profesión que algunas veces cura, otras alivia y siempre acompaña ${ }^{5}$.

Por seu turno, ao ol harmos criticamente para a medicina-ciência, tendo como premissa suasubordinação a um conjunto de valores, nem todos estritamente científicos, que se superpõem na direção de seu fim maior - o bem, a cura -, evidentemente a validação do experimento mé dico que levea alcançar esse objetivo se dará num cenário de tolerância e adaptação epistemológica às suas particularidades.

A demarcação, a mais clara possível, dessa abordagem repousa na separação que deverá estar nítida e cristalina quando, na análise do ato médico, o critério para a sua validação, para a sua legitimidade, não se dê no campo estrito da ética de valores culturais ou socialmente estabelecidos. Enfim, que seja o crivo epistemológico sobrea medicinaum acontecimento científico em si mesmo, como que reconhecendo que se a uma dada ciência éfacultada a finalidade de uma idéia de valor, no caso a realização do "bem", a ciência, ela mesma, deverá se auto-avaliar no ato de avaliar.

Parece não importar muito, se formos nesta linha, se a filosofia da ciência percorrer caminhos heterodoxos na obediência aos seus postulados, rompendo com pacotes muitas vezes fechados de dogmas metodológicos e normativos. Relativismo, talvez, mas muito mais mutações paradigmáticasa la Kuhn: algo como sea própria epistemologia estivesse sujeita às instabilidades paradigmáticas, devendo, às vezes, migrar de uma epistemologia "normal" para uma epistemologia "revolucionária".

Como definir, por exemplo, diante da avalia- ção do comportamento científico ou não de um ato médico, numa contenda jurídica, ética, moral, social ou técnica, se não pela própria validação científica do mesmo, sobreposto àquelas variáveis, de modo a justificá-lo ou condená-lo? Dessemodo, entendemos quea medicina-ciência e as especialidades médicas serão, como subciências, alvo de ol hares epistemológicos sobresi, em que, ao fim, feito o percurso canônico adequado, deverão estar legitimadas perante a ciência "oficial". Ou deveriam estar como salvaguarda de uma práxis abrigada no seio da ciência, e que desta não se espera um ato de não-reconhecimento da medicina-ciência, como se a ciência pudesse abandonar a medicina à própria sorte, por ter como objeto finalístico o "bem".

O corre que no caso da subciência dita M edicina do Trabalho, o paradigma da cura edo "bem" como ato finalístico da medicina é violado, peremptoriamente violado. Esse pode ser o calcanhar-de-aquiles da abordagem epistemológica e sua competência no tocante à medicina-ciência. Esta é a nossa discussão.

M edicina do Trabalho - subciência médica?

Antes, quando a medicina não comportava especialidades, havia uma natural abordagem holística do ser humano em que a medicina buscava o "bem" finalístico da cura, independentemente dos fatores determinantes dos desequilíbrios do "andar natural das coisas da vida". À medida que se complexificaram as variáveis de abordagem, e o conhecimento científico foi se acumulando, a medicina-ciência foi se subdividindo para dar conta dos níveis de exigência requeridos nos campos específicos do conhecimento necessário para atingir o "bem" finalístico.

Assim, podemos dizer que o grau ea intensidade de especialização da medicina deram-se no marco do avanço tecnológico, a partir da acumulação de experimentos científicos e sua validação no ambiente legitimado da ciência oficial: a academia, as instituições de pesquisa e a imprensa científica oficial. Entre algumas vertentes da pesquisa científica que deram suporte e legitimação para a conformação de uma medicinaciência e sua gradual, e ainda inacabada, subdivisão em especialidades, podemos citar: a bacteriologia, a fisiologia, a farmacologia, a imagenologia, a computação científica, a energia nuclear, etc.

Criado o especialista, nesse processo de 
evolução científica dosinstrumentos emeios para aprimorar o "bem" finalístico da cura, o cardiologista passou a ser um médico, que executa um ato médico, cujo objeto é alcançar o "bem" do coração do paciente. Também assim foi com o pneumologista, o dermatologista, o ginecologista, o psiquiatra e todos os demais especial istas dentro da plêiade de subciências médicas, hoje sobejamente conhecidas e definitivamente estabelecidas.

Nesse espectro, é bem evidente a tríade começo-meio-fim da práxis médica. Se no início da abordagem em busca da cura, o médico observa que a cura depende do "bem" do coração do paciente, eque para isso énecessário um ol har específico e mais aprofundado de seus meandros, o cardiologista assume o caso em ato médico continuado e coerente com o aspecto finalístico da medicina-ciência.

Sem entrar no mérito e na crítica desse modelo de fragmentação interminável da medicina, pois não é esse o foco da nossa discussão, existe uma coerência científica das subciências médicas para se chegar ao objetivo maior da medicina-ciência.

Pois que à M edicina do Trabalho (MT) não se passa esta índole. A rigor, a MT deveria ser a especialização médica que visa a aprofundar o olhar médico para aquelas enfermidades que, originadas na relação trabalho-saúde, pudessem em ato médico continuado e coerente alcançar 0 "bem" finalístico da medicina-ciência. Não é, contudo, esta a finalidade da MT, posto que sua posição institucional não éa de tratar e, em conseqüência, buscar o "bem" do paciente, mas antes, ao avaliar a capacidade física do trabalhador de poder continuar ou não trabalhando, muitas vezes 0 ato médico se traduz na devolução do paciente às fontes determinantes de seu mal-estar original. Em outras palavras, o médico do trabalho não se situa no mundo do trabal ho, eneste institucionalmente se insere como "verdadeiro" médico e agente facilitador da cura. 0 verdadeiro, aqui propositalmente aspeado, tem a conotação assumida neste debate da verdade científica conferida ao ato médico, embasado no conhecimento científico e levado ao extremo na comprovação de atingir seu objetivo, ou seja, sujeito à validação científica na medida do alcance do "verdadeiro" objeto finalístico, qual seja, o da cura.

Em outra situação, se um médico do trabaIho observa um trabal hador com problema cardíaco, não é el equeo tratará, mas o cardiologista que deverá ser acionado, assim como o pneumologista, no caso das pneumoconioses, e o derma- tologista, no caso das dermatoses ocupacionais, entre outros tantos casos exemplares. Poderia ser, então, a M T uma clínica geral voltada para os trabalhadores, no tocante aos seus males originados no trabalho? Do mesmo modo, a resposta também é não, na medida em que o médico do trabalho não tem como missão tratar do trabaIhador, propiciar a cura de seus males, mas somente avaliar sua capacidade física de continuar ou não trabalhando. No máximo, em situaçõeslimite de mal-estar dos trabal hadores, capazes de impedir ou comprometer a capacidade de trabaIhar, o médico do trabalho pode agir como bloqueador desse mal-estar, pela via da medicalização paliativa de sintomas diversos ou pelo afastamento temporário, pelo menor tempo possível que as exigências do processo produtivo permitam. Caso o problema de saúde seja grave, a ponto de comprometer mais definitivamente 0 trabalhador como elemento da produção, 0 afastamento poderá ser definitivo, eo problema desaúde/doença será resolvido por outro médico e, não, pelo médico do trabalho.

Sendo assim, cabe outra pergunta: a MT trata, então, de quê? Por certo não é do trabalhador, porquanto, como vimos, foge ao seu escopo de atuação. Não há o objeto finalístico da cura no ato do médico do trabal ho. Seu ato se restringea servir como intermediador dos danos infligidos à força de trabal ho, estabelecendo critérios, não para o diagnóstico do dano (ou doença) em si, mas para o diagnóstico de aptidão para que 0 "paciente" continue trabalhando ou não.

0 ato médico na M T configura-se, portanto, em ato intermediador, filtrante, de avaliação da aptidão do trabalhador para seguir ou não sua jornada, ou de se o "paciente" deve ou não realmente ir ao "verdadeiro" médico.

Ao médico do trabal ho caberá um outro tipo deato finalístico: o deavaliar sehá condições para manutenção daforça detrabal ho na linha deprodução. Em última instância, não parece haver qualquer proximidade com o objeto da medicina-ciência. Será então uma fraude a MT como subciência médica? Sim ou não, como dirimir epistemologicamente esta questão?

0 binômio prevenção-cura aflora nesta discussão. Secularmente, a medicina navegou e desfraldou suas vel as no oceano da cura, eassim ainda o é. Entra em cena o não menor universo das ciências da saúde e seus postulados da prevenção, e não mais o (restrito) campo da medicinae os seus postulados curativos, em última instância. O u, mais precisamente, um campo teleologicamente mais abrangente além do da cura: 0 da "cura antecipada". 
Pois bem que se tem, aqui, um novo dilema. Seriam as chamadas ciências da saúde ciências mesmo? Pois quese vão, do mesmo modo, se pautar em tributários científicos inequívocos, tais como a epidemiologia, as engenharias, a genética, a estatística eas matemáticase, entre outras, a própria medicina-ciência, para dar concretude a seus objetivos eformulações, calcadas na pesquisa e na observação empírica prospectiva e ajustável, as ciências da saúde parecem ter em si a seiva da ciência stricto sensu.

É evidente que, do mesmo modo que a medicina, as ciências da saúde também se fundam em variáveis sociais, culturais, políticas e econômicas, não tão científicas, mas que não Ihes retiram o caráter de ciências, tal vez rotuladas no plural para, justamente, firmar o seu caráter plural e conferir-Ihes, assim, o grau de ciências lato sensu.

E, assim, as chamadas ciências da saúde surgem no cenário como evidente contraponto, não propriamente antagônico ao paradigma médico, emais como polegar eindicador fazendo, na rota da modernização do pensamento científico quanto aos fatores causais dos males que afligem a saúde das pessoas, uma "pinça evolutiva" sanitarista ( polegar eindicador se encontrando - medicina esaúde), resgate- ou inauguração - deuma abordagem mais decisiva para mudar o rumo do "andar natural das coisas da vida", evitando ou impedindo aquilo que possa acar retar mudanças de um andar natural "saudável", ou intervindo no mesmo. Ou, o mais saudável possível, considerados os fatores culturais implicados em sua concepção.

$E$, pois, que a intervenção sobreos fatores determinantes dos desequilíbrios à saúde calca-se num novo paradigma, inicialmente 0 da saúde pública, depois saúde coletiva, às vezes ( $\mathrm{mal}$ ) rotulado de medicina social e, mais recentemente, o da promoção da saúde, ainda confuso na de marcação de seus limites.

D efinem-se, a partir disto, dois grandes pólos, grosso modo: o da medicina (paradigma curativo) propriamente dita e o da saúde pública (paradigma preventivo), como todos sabemos. Ou a medicina-ciência cuida de curar ou as ciências da saúde cuidam de evitar a necessidade de curar.

Para a Saúde Coletiva a análise crítica da me dicina representa duplo desafio: "epistemológico", dada a complexidade dos objetivos envolvidos no estudo; e "ético", uma vez que uma vertente de intervenção está presente com maior ou menor intensidade nesta área [... $]^{9}$.

Sea MT não seinserena medicina (curativa), como visto, poderia então estar inserida na saúde pública (preventiva)? Vejamos.

A M T nasce fora do paradigma da saúde pública e fora dela permanece na maioria dos países do mundo. A rigor, o único país de estrutura capitalista que intenta resgatar o campo das relações saúde trabalho para o espectro de abrangência das políticas públicas de saúde ou, meIhor, políticas de saúde pública, é o Brasil, a partir da Lei Orgânica da Saúde, de 1990, no marco da estruturação do sistema e dos serviços de saúde. É bem verdadequea Itália, fonte inspiradora da chamada "saúde do trabalhador" no Brasil, também se arvorou nesta ousadia de pensar a $M T$, ou medicina das fábricas como chamavam os italianos, como campo de intervenção das políticas de saúde e de suas estruturas públicas. Caminho contra-hegemônico interrompido pela integração européia e os novos cenários políticos que influenciaram na deflagração de uma conjuntura desfavorável à consolidação desse modelo inovador na Itália atual.

A tentativa de resgate da MT para o campo da saúde pública, no Brasil, como ferramenta técnica componente da área de saúde do trabalhador, calcou-se, então, na intenção de mudar o seu paradigma, centrado em algumas linhas principais:

- A compreensão de quea matéria de quetrata a MT - relações saúde-trabalho - situa-se no campo da saúde pública e não no campo das relações de trabalho e previdência, como é o modelo vigente na maioria dos países;

- A mudança de enfoque: direito à saúde e segurança no trabalho com base em relações de contrato e delimitações normativas restritivas, para o de direito à saúde, amplo e irrestrito;

- A ampliação do modelo de intervenção sobreosfatores determinantes dos danos, com base na vigilância da saúde e não no model o fiscalizador da norma; e, principalmente, como ponto de essência;

- A incorporação do trabal hador como sujeito coletivo na definição das práticas e elemento decisivo na transformação dos processos de trabalho.

0 movimento de reformulação do paradigma da MT para esse campo rotulado de Saúde do Trabalhador (ST), consolidado na lei do SUS e incorporado gradativamente nos últimos anos pelas áreas das relações saúde- trabal ho no âmbito acadêmico, sindical e dos serviços de saúde, partiu da premissa de que o campo das relações saúde-trabalho tenderia a uma evolução natural, no aspecto dos campos de conhecimento que lhe 
dizem respeito. Assim, a M T, hoje sendo superada pelo campo da saúde ocupacional, estaria caminhando para o campo da saúde do trabalhador ou, em última instância, da saúde pública.

Essa evolução conceitual e operacional, em primeira instância da MT para a saúde ocupacional, estaria respondendo a uma relativa impotência da medicina do trabalho para intervir sobre os problemas de saúde causados pelos processos de produção com uma 'resposta racional, 'científica' e aparentemente inquestionável" no sentido de ampliar a atuação médica, intervindo sobre 0 ambiente de trabal ho, com a concorrência de outras disciplinas do conhecimento ${ }^{10}$.

Do mesmo modo, em segunda instância, a "passagem" da "saúde ocupacional" para a "saúde do trabalhador" teria se dado em função de o modelo da saúde ocupacional - desenvolvido para atender a uma necessi dade da produção - não ter conseguido atingir os objetivos propostos. Entre as razões que justificam o fato, assinala-se: o modelo mantém o referencial da medicina do trabalho [...] não concretiza o apelo à interdisciplinaridade [...] [e] apesar de enfocar a questão no coletivo de trabalhadores, continua a abordá-los como "objeto" das ações de saúde [...] $]^{10}$.

Nesse contexto, a formulação de um novo campo de atuação das ciências da saúde (pública, coletiva) - o da "saúde do trabalhador" - atuaria em expressão de contra-hegemonia, superando a saúde ocupacional e absorvendo a M T como simples "ferramenta técnica" de apoio ao desenvolvimento das linhas antes citadas que compõem seu paradigma.

$\mathrm{O}$ paradigma secularmente al icerçado na M T clássica daria, desse modo, lugar a um novo enfoque técnico-científico, em que a ênfase mudaria da devolução do trabalhador ao processo de trabalho em regime de risco à saúde, para o de transformação dos processos e ambientes de risco em outros que fossem garantidores da saúde.

Ocorre que, evidentemente, a M T não poderia cumprir esse papel, seja por se tratar de ferramenta da gestão de pessoas na linha de produção, no sentido de avaliar sua capacidade biológica de trabalhar ou não, seja por estar impedida de fazêlo por obediência à norma, ou seja, ainda por estar implícita ou explicitamente constrangida a não colidir com o interesse maior dos processos produtivos, qual seja, o de produzir. E produzir com o menor custo, a maior rapidez e a maior eficiência, em que a saúde - insumo da força de trabalho - é condição mediadora, e não objetal, do processo produtivo. Mais decisivamente se poderia acrescentar que à MT jamais poderia se atribuir a decisão de transformar os processos de risco à saúde no trabalho, por não ser de sua alçada a formatação, a organização e a manutenção dos processos produtivos, logicamente.

Comparação entre a atuação do médico do trabal ho e do profissional clássico de saúde pública, em que se poderia alegar que, do mesmo modo que um sanitarista nada pode fazer para evitar a desnutrição, causada pela fome, ou as doenças decorrentes da ausência de saneamento básico, pela incapacidade de influir diretamente no processo político e/ou no modelo econômico que as acarreta, não se sustenta. A saúde pública, ao trabalhar no marco da preven ção, lidando com os determinantes desdeseu reconhecimento, sistematização das informações quelhes desnudam e proposição de soluções para sua eliminação, atua necessariamente no paradigma contra-hegemônico ao processo de sustentação desses determinantes.

Demodo semelhanteà medicina-ciência, parece ser o objeto finalístico da saúde pública o "bem" coletivo, a "cura antecipada" a partir da intervenção sobre os determinantes dos danos à saúde, não mais do paciente, mas das pessoas em geral.

O distanciamento da saúde pública entre a formulação técnica, com base nas disciplinas do conhecimento que lhe dão suporte (comportamento científico), ea capacidade de resolver problemas em nível decisório (comportamento político) não Ihe retira a identidade científica, no campo das "ciências da saúde" lato sensu, mantendo-a capacitada a servir-se de parâmetros científicos para propor mudanças no cenário político e no modelo econômico, inclusive os relacionados aos problemas presentes nos processos produtivos. Ou seja, a incapacidade da saúde pública de resolver muitos problemas não se deve à incapacidade de revelá-los e relevá-los, assim como à medicina-ciência é reservada a incapacidade de resolver outros tantos, a despeito detentar escrutiná-los e tratá-los.

A MT, ao contrário, atua como braço de perpetuação da hegemonia dos processos de sustentação dos determinantes dos danos na relação saúde trabalho ao legitimá-los, na medida de sua atuação como elemento filtrante da aferição da intensidade dos danos à saúde. De outra forma, também, diante dos riscos presentes nos ambientes e processos de trabalho, a MT age como elemento "científico" ao corroborar e auxiliar no aperfeiçoamento e na utilização de equipamentos que transferem ao corpo do trabalhador a 
responsabilidade de proteção contra os riscos: equipamentos de proteção individual ${ }^{11}$. Além disto, a M T atua como sensor de avaliação do nível de agentes físicos e químicos tóxicos, estabelecidos em normas - limites de tolerância de exposição no ambiente de trabalho.

Parece estarmos diante de um dilema epistemológico ao olhar a M T como subciência médica, na medida em que não cumpre o objeto finalístico da medicina-ciência. Do mesmo modo, na tentativa de migração de seu paradigma curativo para o preventivo, colocando-a como área afim ao campo da saúde pública, também não se observa o cumprimento do objeto finalístico das ciências da saúde.

Nem pretende e tampouco exibe competência científica para a cura - 0 "bem" individual (medicina-ciência), nem para a "antecipação da cura coletiva" (ciências da saúde - saúde pública/saúde coletiva).

Em outras palavras, o eventual comportamento "científico" da MT antes se aproxima, e mesmo confunde-se ao comportamento político de bem cumprir a norma contratual, ao contrário do que ocorre com a saúde pública, cujo distanciamento entre o comportamento científico e o comportamento político não Ihe retira o caráter finalístico de buscar o bem da coletividade, inclusive de trabalhadores nas linhas de produção.

Corrobora a dificuldade de compreensão da $M T$, como subciência, quando se sabe que a norma contratual é expressão hegemônica de manutenção do corpo do trabalhador como força de trabalho capaz de manter sua capacidade de produzir para o ato finalístico do processo deprodução: a produção, e não o aprimoramento do "andar natural das coisas da vida".

De que se trata, então, a M edicina do TrabaIho? Vamos tentar definir.

\section{M edicina do Trabal ho - de que se trata?}

A descrição de doenças relacionadas ao trabalho ocorre desde a mais remota Antigüidade, em papirosegípcios, textos judaicos, evidentementeem Hipócrates, Platão, Aristóteles, Plautus, Virgílio, Plínio, o velho, Lucrécio, chegando a Galeno, entre tantas citações ao longo da história ${ }^{12}$.

Pouco a pouco, ainda na Idade M édia, as doenças relacionadas ao trabalho foram sendo observadas com maior detalhamento, com Avicena (980-1037), que descreveu a cólica plúmbica, com Dickerson observando a saúde de trabalhadores em catedrais, com Ellenborg (1440-1499), queescreve um livro sobre os riscos dos ourives, com Vigo, sobre a febre dos marinheiros e, entre outros, com Agrícola, sobre a asma dos mineiros ${ }^{13}$.

Embora muito se tenha produzido e até sistematizado sobre essas doenças, é em 1700 que Bernardino Ramazzini (1633-1714), médico italiano, com sua obra De M orbis Artificum Diatriba (Tratado sobre as Doenças dos Trabalhadores), vai estabelecer uma sistematização e uma amplitude sobreo tema atéentão não experimentada, a ponto de ser "impropriamente" reconhecido como o pai da Medicina do Trabalho.

Impropriamente, assumimos, pois cremos que o célebree genial médico provavelmentenão gostaria deser tido como o fundador de uma prática, cuja possibilidade de reconhecimento e diagnóstico de doenças ea capacidade de poder resolvê-las estivessem condicionadas a normas, limites efronteiras duvidosas entre o dano efetivo à saúde e o estabelecido em contratos de trabaIho, em tudo contrário ao que ressaltava: Das oficinas dos artífices, portanto, que são antes escolas de onde saí mais instruído, tudo fiz [...], sobretudo, o que é mais importante, saber aquilo que se pode sugerir de prescrições médicas preventivas ou curativas contra as doenças dos operários. ${ }^{14}$ Professor que foi, diante da necessidade de agregar a categoria trabalho ao rol de determinantes dos malesqueafligiam as pessoas, Ramazzini, no prefácio de sua magnífica obra, assinalava que se deveria acrescentar à anamnese hipocrática clássica a pergunta "e que arte exerce?" 14 .

Considerando que o "ato médico laboral" traduz uma espécie de desconstrução do ato médico clássico, como representação simbólica de uma "cultura de limites", Waissmann ${ }^{12}$ assinala quea M T tem como objetivo básico a não culpabilidade do trabal ho na gênese de patologias, cuja ação médica é dirigida à adequação dos indivíduos à produção e voltada para as patologias individuais" para evitar que efeitos aparentes nos coletivos [de trabalhadores] pudessem vir a esclarecer vínculos entre el es e o trabalho".

Nesse sentido, o "pai" da M edicina do TrabaIho seria Robert Baker: A M edicina do Trabalho enquanto especialidade médica surge na Inglaterra, na primeira metade do século XIX com a Revolução industrial. Naquele momento, o consumo da força de trabalho, resultante da submi ssão dos trabalhadores a um processo acelerado edesumano de produção, exigiu uma intervenção, sob pena detornar inviável a sobrevivência e reprodução do próprio processo. Quando Robert Dernham, proprietário de uma fábrica têxtil, preocupado com o fato 
de que seus operários não dispunham de nenhum cuidado médico... procurou o Dr. Robert Baker, seu médico, pedindo que indicasse qual a maneira pela qual ele, como empresário, poderia resolver tal situação, Baker respondeu- Ihe: "Coloqueno interior de sua fábrica o seu próprio médico, que servirá de intermediário entre você, os seus trabalhadores e o público"10 (grifo nosso).

Como vemos, o papel intermediador do mé dico do trabalho entre patrão e empregados bem se ressalta desde a sua origem. Seria este fator intermediário o de mitigar conflitos? Ou seria de selecionar os melhores? Ou, ainda, como assinalava Henry Ford, fator delucratividade? : "O corpo médico éa sessão deminha fábrica que medá mais lucro."15.

Para tentar responder a estas questões, é necessário continuar com Baker, que assinalava ainda: D eixe 0 [ o médico do trabalho] visitar a fábrica sala por sala, sempreque existam pessoas trabaIhando, de maneira que ele possa verificar o efeito do trabal ho sobre as pessoas. E se el e verificar que qualquer dos trabalhadores está sofrendo a influência de causas que possam ser prevenidas, a ele competirá fazer tal prevenção $0^{10}$.

Fica patente o espírito hipocrático de Robert Baker, quando recomenda que o médico percorra todo 0 ambiente de trabal ho e conheça os processos produtivos capazes de provocar dano à saúde, para, em consonância com o ente finalístico da medicina, promover o bem do paciente. E com este mesmo espírito continua Baker: Dessa forma vocêpoderá dizer: meu médico éa minha defesa, pois a ele dei toda a autoridade no que diz respeito à proteção da saúde e das condi ções físicas demeus operários: sealgum deles vier a sofrer qualquer alteração da saúde, o médico unicamente é que deve ser responsabilizado. ${ }^{10}$

Ao chamar a si a responsabilidade so brea saúde dos trabalhadores, acreditando que poderia intervir nos processos produtivos, Baker reitera o caráter finalístico da medicina vigenteà época, e não sujeita, ainda, a outras variáveis que não a desuafinalidade. 0 queBaker, segundo suas próprias observações, não imaginava éque ao médico jamais seria facultada a possibilidade de alterar os processos de trabalho com o objetivo de eliminar riscos à saúde. Ou seja, inaugurada a M edicina do Trabalho, de imediato rompe-se 0 elo que a uniria ao objeto maior da medicinaciência: o bem ou a cura.

\section{M edicina do Trabal ho: subserviência}

A rigor, o quefaz então a M edicina do Trabalho? A profissão médica caracterizou-se, ao longo da história, como profissão tipicamente liberal, cuja práxis alcança nossos dias, embora cada vez mais os médicos venham se assalariando e proletarizando.

Em virtude desta prática histórica, o consultório médico é uma instituição solidamente reconhecida esocialmente legitimada, especialmente nos países capitalistas, como o espaço de exercício livre da medicina, onde o paciente vai buscar a sua cura.

Como já vimos, o trabalhador enfermo de uma doença relacionada claramente ao trabalho não procurará um consultório de médico do trabalho para curar-se, mas sim o do "verdadeiro" médico capaz de curá-lo. Se, por coincidência, estefor também médico do trabal ho, o papel que exercerá em seu consultório não será, evidentemente, o de médico do trabal ho, mas o de clínico geral ou especialista clínico, ou de cirurgião.

O u seja, a posição demédico do trabalho será "sempre" a de médico subordinado a um contrato que o coloca na posição de cumpri-lo para servir como elemento filtrante da força de trabaIho capaz ou incapaz de seguir trabalhando, em função de sua aptidão ou condição laborativa. A Medicina do Trabalho exercida em consultório médico serve, apenas, para a realização de exames vinculados a contratos de trabalho, tais como exames admissionais, periódicos, demissionais e periciais.

Trata-se, portanto, de uma inequívoca posição institucional mente estatuída de controle da força de trabalho a serviço do contratante. 0 contratante do médico do trabalho, por sua vez, é 0 mesmo contratante da força de trabalho em pregada no processo produtivo. Desse modo, reserva-se ao médico do trabalho um papel intermediador (como previa Baker) do contrato de trabalho, no sentido de fazer valer o contrato e não o "bem" finalístico da cura individual, ou o "bem" finalístico da antecipação da cura coletiva ( como não previa Baker).

Responsabilizado por essa intermediação, ao assumir um papel controlador, o médico do trabalho, para bem servir ao seu desígnio, também contratual, necessariamente assume um perfil de subserviência ao contratante, como instância "responsável" pelo controle da força de trabalho.

A expressão "controle" étão marcantena M T, quea norma brasileira (Norma Regulamentadora - NR-7) que estabelece a obrigatoriedade da 
elaboração e implementação, por parte de todos os empregadores e instituições que admitam trabaIhadores como empregados [...] com o objetivo de promoção e preservação da saúde do conjunto dos seus trabalhadores ${ }^{16}$, a cargo do médico do trabaIho, chama-se Programa de "Controle" M édico de Saúde Ocupacional (grifo nosso).

A despeito dehaver uma clarainspiração ideológica na modelagem do paradigma da chamada saúde do trabal hador, centrada na concepção marxista de luta de classes, em que as questões pertinentes ao binômio saúde-trabal ho estariam involucradas nas relações capital-trabalho, sem discordar deste enfoque, não tratamos propriamente aqui de analisar a MT como subciência médica subserviente ao capital.

Em verdade, a expressão subserviência que intentamos repousa no fato de que a M T contradiz a teleologia médica e se configura como uma área de gestão de pessoas, e não de "gestão" da saúde das pessoas, no sentido inequívoco da cura de seus males.

Grosso modo, pode-se dizer que o mercado de trabalho que absorve o médico do trabal ho, no Brasil, centra-se em três ramos:

1) o médico do trabalho que, direta ou indiretamente, serve a um empregador público ou privado como controlador da força de trabal ho;

2) o médico do trabalho que serveao aparato estatal de fiscalização da norma trabal hista de saúde e segurança do trabalho, servidor do $\mathrm{M} \mathrm{i-}$ nistério do Trabalho;

3) o médico do trabalho que serve como perito judicial, nomeado pelo juiz em contendasjudiciais trabal histas, praticamente para avaliação da pertinência ou não de percepção dos adicionais de insalubridade e de periculosidade, regidos pelas Normas Regulamentadoras de números 15 e $16^{16}$.

Em outras situações passíveis de arregimentação do médico do trabalho, tais como a perícia previdenciária de nexo laboral de doença, efetuada pelo Instituto Nacional do Seguro Social (INSS), e em perícias judiciais de nexo causal, com o trabalho para apuração de responsabilidade civil ou criminal, não existe a exigência de diploma de médico do trabalho.

No primeiro caso, é nítido o perfil de servilismo do exercício profissional. Já no caso do fiscal do M inistério do Trabalho, a submissão ocorre numa escala hierárquica acima: a de fiscal controlador do controlador, na medida em que o "bem finalístico" da medicina continua sendo preterido em prol da fiscalização e bom cumprimento da norma de controle da força de trabalho.
No caso do perito, a subserviência, do mesmo modo, étotal à norma que rege as controvérsias da contenda judicial.

Em todos os casos, ainda que imbuído de generosidade e índole hipocrática para com a força de trabalho, no sentido de propiciar o "bem" ao coletivo de trabal hadores, o médico de trabaIho fica impedido de fazêlo, por sua posição institucionalmente estabelecida, salvo dentro do limite estrito (e limitado) da norma contratual.

Nos casos em que não existe norma contratual, a abordagem dos problemas relacionados ao binômio saúde-trabalho, desde a intervenção sobre os fatores determinantes dos agravos até a sua reparação, é realizada por profissionais que prescindem de qualquer identidade cognitiva, corporativa, deontológica, ideológica ou ética com a M T. São eles, entre os diversos profissionais capazes de cumprir esse papel: o sanitarista, o epidemiólogo, o toxicologista, o psicólogo, o antropólogo, o cientista social e o "verdadeiro" médico.

\section{Conclusão}

Ao que se pretendia, inicialmente, ao tentar resgatar a M T para o campo da saúde pública, como "ferramenta técnica" contributiva, contrapõe-se uma questão: qual conteúdo técnico oferecea M T para a constituição de um acervo de conhecimentos capazes de intervir sobre os fatores implicados na relação saúde-trabal ho? A rigor, nenhum e, antes, ao contrário. Em outras palavras, na constituição de um ambiente interdisciplinar como, por exemplo, na composição de forçatarefa de escrutínio sobre a relação saúde-trabaIho, não cabe qualquer papel contributivo à $M T$, pois sua finalidade como elemento filtrante da força de trabal ho é objeto de análise como mantenedor dos fatores determinantes dos agravos, e não como sujeito técnico de mudança destes fatores.

Em síntese, submeter ao crivo epistemológico o contingente de aplicativos da M edicina do Trabalho, muitos deles baseados em conhecimentos científicos, e enten dêlos como corolários deum pragmatismo subservientea fatores determinantes que fogem à sua capacidade de intervenção para cumprir a finalidade da medicina-ciência, mais do que buscar o exercício em si mesmo da crítica, pretende retomar o debate sobre a questão e, se possível, recolocá-lo no campo da saúde pública, em específico, na saúde do trabalhador. 


\section{Colaboradores}

LCF Vasconcellos e WA Pignati participaram igualmente de todas as etapas da elaboração do artigo.

Agradecimentos

A Fermin Roland Schram, pelo incentivo para publicar este artigo.

\section{Referências}

1. Popper K. A lógica da pesquisa científica. São PauIo: Cultrix, Edusp; 1975.

2. Kuhn T. The structure of scientific revolutions. Chicago: Chicago University Press; 1972.

3. Canguilhem G . O normal e o patológico. Rio de Janeiro: Editora Forense Universitária; 1978.

4. Ortega y Gasset J. M isión de la universidad. Obras completas. Tomo IV. Madrid: Revista de Occidente; 2003.

5. Gallego R. Es la medicina una ciencia? [acessado 2003 Ago 28]. Disponível em http://www. encolombia. com/pediatria34499 lamedicina.htm.

6. Galeno. La M edicina Alejandrina. [acessado 2003 Out 06]. Disponível em http://escuela.med.puc.cl/ publ/H istoriaM edicina/ AlejandrinaGaleno.html.

7. Hipócrates de Cós. Juramento de Hipócrates. [acessado 2003 Out 06]. Disponível em http://www. gineco.com.br/jura.htm.

8. Kipper JD, Clotet J. Princípios da beneficência e não-maleficência. In: I biapina SFC, Garrafa V, OseIka G, organizadores. Iniciação à bioética. Brasília: Conselho Federal de M edicina; 1998; p. 37-52.

9. Camargo Jr. KR. Biomedicina, saber e ciência: uma abordagem crítica. São Paulo: Editora Hucitec; 2003.
10. Mendes R, Dias EC. Da medicina do trabalho à saúde do trabalhador. Rev Saúde Púb 1991; 25(5): 341-349.

11. Porto MFS. Aspectos conceituais sobre risco tecnológico. Rio de Janeiro: CESTEH/ENSP/Fiocruz; 1991. [M imeo].

12. Waissmann W. A "cultura de limites" e a desconstrução médica das relações entre saúde e trabalho. [tese]. Rio de Janeiro: Escola Nacional de Saúde Pública, Fundação Oswaldo Cruz; 2000.

13. Mendes R, Waissmann W. Aspectos históricos da patologia do trabalho. In: Mendes $R$, organizador. Patologia do trabalho. São Paulo: Editora Atheneu; 2003; p. 3-46.

14. Ramazzini B. As doenças dos trabalhadores. São Paulo: Editora Fundacentro; 2000.

15. Oliveira JAA, Teixeira SM F. (Im) previdência Social - 60 anos de história da Previdência no Brasil. Pe trópolis: Editora Vozes; 1986.

16. Portaria 3214/78. Aprova as Normas Regulamentadoras (NR's), do cap V da CLT. In: Segurança e Medicina do Trabalho. São Paulo: Editora Atlas; 2001.

Artigo apresentado em 13/01/2005

Aprovado em 12/09/2005

Versão final apresentada em 17/11/2005 